\section{OPEN ACCESS}

Edited by:

Kimberly J. Saudino,

Boston University, United States

Reviewed by:

Alexis Edwards,

Virginia Commonwealth University,

United States

Carol Van Hulle,

University of Wisconsin-Madison,

United States

*Correspondence:

Man K. Xu

man.k.xu@gmail.com

${ }^{\dagger}$ These authors have contributed equally to this work.

Specialty section

This article was submitted to Personality and Social Psychology, a section of the journal

Frontiers in Psychology

Received: 29 March 2017 Accepted: 20 September 2017 Published: 11 October 2017

Citation:

Xu MK, Gaysina D, Tsonaka R, Morin AJS, Croudace TJ, Barnett JH, Houwing-Duistermaat J, Richards M,

Jones PB and the LHA Genetics Group (2017) Monoamine Oxidase A (MAOA) Gene and Personality Traits from Late Adolescence through Early Adulthood: A Latent Variable Investigation. Front. Psychol. 8:1736.

doi: 10.3389/fpsyg.2017.01736

\title{
Monoamine Oxidase A (MAOA) Gene and Personality Traits from Late Adolescence through Early Adulthood: A Latent Variable Investigation
}

\begin{abstract}
Man K. Xu ${ }^{1,2,3,4 * t}$, Darya Gaysina ${ }^{5 \dagger}$, Roula Tsonaka ${ }^{2}$, Alexandre J. S. Morin ${ }^{6}$, Tim J. Croudace ${ }^{7}$, Jennifer H. Barnett ${ }^{8}$, Jeanine Houwing-Duistermaat ${ }^{2}$, Marcus Richards ${ }^{9}$, Peter B. Jones ${ }^{3}$ and the LHA Genetics Group
\end{abstract}

${ }^{1}$ Faculty of Psychology and Educational Sciences, Welten Institute, Open University of the Netherlands, Heerlen, Netherlands, ${ }^{2}$ Department of Medical Statistics and Bioinformatics, Leiden University Medical Centre, Leiden, Netherlands, ${ }^{3}$ Department of Psychiatry, University of Cambridge, Cambridge, United Kingdom, ${ }^{4}$ Department of Psychology, Education, and Child Studies, Erasmus University Rotterdam, Rotterdam, Netherlands, ${ }^{5}$ EDGE Lab, School of Psychology, University of Sussex, Brighton, United Kingdom, ${ }^{6}$ Substantive-Methodological Synergy Research Laboratory, Department of Psychology, Concordia University, Montreal, QC, Canada, ${ }^{7}$ School of Nursing and Health Sciences, University of Dundee, Dundee, United Kingdom, ${ }^{8}$ Cambridge Cognition, Cambridge, United Kingdom, ${ }^{9}$ MRC Unit for Lifelong Health and Ageing at UCL, London, United Kingdom

Very few molecular genetic studies of personality traits have used longitudinal phenotypic data, therefore molecular basis for developmental change and stability of personality remains to be explored. We examined the role of the monoamine oxidase A gene (MAOA) on extraversion and neuroticism from adolescence to adulthood, using modern latent variable methods. A sample of 1,160 male and 1,180 female participants with complete genotyping data was drawn from a British national birth cohort, the MRC National Survey of Health and Development (NSHD). The predictor variable was based on a latent variable representing genetic variations of the MAOA gene measured by three SNPS (rs3788862, rs5906957, and rs979606). Latent phenotype variables were constructed using psychometric methods to represent cross-sectional and longitudinal phenotypes of extraversion and neuroticism measured at ages 16 and 26. In males, the MAOA genetic latent variable (AAG) was associated with lower extraversion score at age 16 $(\beta=-0.167 ; \mathrm{Cl}:-0.289,-0.045 ; p=0.007, \mathrm{FDRp}=0.042)$, as well as greater increase in extraversion score from 16 to 26 years $(\beta=0.197$; Cl: $0.067,0.328 ; p=0.003$, FDRp $=0.036$ ). No genetic association was found for neuroticism after adjustment for multiple testing. Although, we did not find statistically significant associations after multiple testing correction in females, this result needs to be interpreted with caution due to issues related to $x$-inactivation in females. The latent variable method is an effective way of modeling phenotype- and genetic-based variances and may therefore improve the methodology of molecular genetic studies of complex psychological traits. 


\section{INTRODUCTION}

Personality traits, such as neuroticism and extraversion, are relatively stable during adulthood (Roberts et al., 2008); however their mean levels are subject to change from adolescence through early adulthood (Roberts and DelVecchio, 2000; Soto et al., 2011; Specht et al., 2011). It is known that personality traits are heritable polygenic traits (Bouchard and Loehlin, 2001; Ebstein, 2006; Pilia et al., 2006; Benjamin et al., 2008; Vernon et al., 2008; Distel et al., 2009), with quantitative behavioral genetic studies suggesting that genetic factors can contribute to stability and age-related changes (Wray et al., 2007; Bleidorn et al., 2009; Kandler et al., 2012). However, no previous studies have investigated associations between specific genetic variation and personality traits from a developmental perspective based on repeated measures of personality traits in adolescence and in early adulthood.

Personality traits have been viewed as endophenotypes for different psychiatric disorders (Terracciano et al., 2010). Indeed, neurobiological correlates, as well as genetic factors, common for personality traits and psychiatric disorders have been found (Foster and MacQueen, 2008; Luciano et al., 2012; Gale et al., 2016; Okbay et al., 2016). Therefore, candidate genes implicated in psychopathology can also be involved in the development of personality traits.

Recent molecular genetic studies have provided multiple lines of evidence supporting the role of the monoamine oxidase A gene $(M A O A)$ in various psychopathologies in adults and children, including antisocial behavior (Fergusson et al., 2011; OuelletMorin et al., 2016), autism spectrum disorder (ASD; Tassone et al., 2011; Verma et al., 2014), and impulsivity (Kinnally et al., 2009; Enoch et al., 2010). MAOA is primarily expressed in catecholaminergic neurons in the human brain (Thorpe et al., 1987), and it preferentially metabolizes serotonin and norepinephrine (Arai et al., 1997). This key function of the $M A O A$ in the central nervous system (CNS) provides the strong rationale for studying $M A O A$ gene in personality and other complex psychological traits.

Studies using MAOA knockout mice models have established that MAOA deficiency leads to neurochemical imbalances, which culminates in neuroanatomical abnormalities such as reduced thickness of corpus callosum, increased dendritic arborization of pyramidal neurons in the prefrontal cortex and disrupted microarchitecture of cerebellum (Bortolato et al., 2013). Human studies have also provided some evidence for the role of common genetic variants in the MAOA function. Specifically, a variable repeat (VNTR) in the 5-flanking region of the MAOA gene demonstrated allele-specific variation in promoter activity in an in vitro assay system (Sabol et al., 1998). Another study (Jansson et al., 2005) showed that in females the $\mathrm{C} / \mathrm{C}$ and $\mathrm{C} / \mathrm{T}$ genotypes of rs979605 (also corresponds to A/A and A/G genotypes of rs979606 in our study) were associated with a significant decrease in thrombocyte-MAO (Trbc-MAO) enzyme activity (expressed as nmoles of 2-phenylethylamine oxidized per minute and per 1010 platelets; Pedersen et al., 1993). In addition, four-SNP haplotype (rs1801291, rs979605, rs6323, rs388863) was associated with Trbc-MAO activity. This association may reflect
MAOA activity in the brain. Alternatively, it is possible that cis-acting regulatory elements within $M A O A$ gene can affect MAOB platelets expression. Another plausible explanation could be that MAOA single nucleotide polymorphisms (SNPs) affected by methylation lead to changes in the expression pattern.

A number of common SNPs were also shown to contribute to allelic mRNA expression in human brain (Pinsonneault et al., 2006). Moreover, there is also evidence for the CNS structural and functional changes related to the MAOA common genetic variants (Manuck et al., 2000; Ducci et al., 2006; Meyer et al., 2006).

To date, there have been few association studies of the $M A O A$ gene and personality traits, with the results being largely inconsistent, likely due to small sample sizes (Jorm et al., 1997, 2000; Eley et al., 2003). Although, there are recent wellpowered large-scale genome-wide association studies (GWAS) of personality traits (Vinkhuyzen et al., 2012; de Moor et al., 2015; Okbay et al., 2016; van den Berg et al., 2016; Lo et al., 2017), the $M A O A$ gene is usually not included in these studies because it is located on the X-chromosome.

Several studies have reported a sexual dimorphic effect of MAOA gene in behavioral traits (Verma et al., 2014), which is indicative of the underlying sexual dimorphism in the regulation of MAOA enzyme (Wu et al., 2009). Moreover, as MAOA activity levels increase with age (Breakefield et al., 1980; Hotamisligil and Breakefield, 1991), the effect of the MAOA gene can be more pronounced at later developmental stages. For example, one study showed that differential associations between the MAOA genotype, neural response and stimuli of social rejection were present among adult females, but not among adolescent females (Sebastian et al., 2010). This observation suggests that as the neural circuits associated with higher mental function continue to develop through adolescence, associations between the MAOA gene and psychological phenotypes, including personality traits, may change during transition from adolescence to adulthood.

In the present study, we investigated the effects of the $M A O A$ genetic variants on extraversion and neuroticism from adolescence (age 16) through early adulthood (age 26), using data from the MRC National Survey of Health and Development (NSHD), also known as the British 1946 birth cohort. We hypothesized that the effects of the MAOA gene on personality traits would change through maturation, and may differ between males and females.

Genetic associations are typically estimated from univariate analysis based on one SNP or several SNPs within a gene region that are analyzed separately. It has been proposed that summary latent genetic variables can better capture genetic variance (Smyrnis et al., 2009; Tsonaka et al., 2012; Bentley et al., 2013). In order to more robustly assess the relationship between $M A O A$ genetic variation and personality traits, a latent genetic variable was created based on three MAOA SNPs: rs3788862, rs5906957, and rs979606.

We also used psychometric methods to model the personality phenotypes at ages 16 and 26 (i.e., cross-sectional model) and the age-related changes from 16 to 26 in the phenotypes (i.e., longitudinal model). The utilization of psychometric latent variable methods is advantageous in that personality phenotypes 
constructed this way are corrected for measurement errors, thus providing more accurate estimations of genetic effects (Xu et al., 2015). This is particularly the case for longitudinal phenotypes, which are especially prone to measurement errors when difference scores are derived from repeated data (Thomas and Zumbo, 2012; Kisbu-Sakarya et al., 2013). Specifically, we use latent difference models (McArdle and Hamagami, 2001) to estimate the age-related changes of extraversion and neuroticism from age 16 to age 26 .

Since the MAOA gene is located on the $\mathrm{X}$ chromosome (Xp11.23), and there is evidence for incomplete inactivation of $\mathrm{X}$-chromosome in females (Berletch et al., 2011), all analyses were performed separately for males (XY karyotype) and females (XX karyotype), in line with other genetic association studies of MAOA (Eley et al., 2003; Liu et al., 2011). Results specific for females were interpreted with caution.

\section{METHODS}

\section{Sample}

The NSHD is a socially stratified birth cohort of 5362 individuals of a white Caucasian background, who have been followed up since their birth in 1946 with multiple data collections across the life course (Wadsworth et al., 2003). At age 53, the blood samples were collected for DNA extraction and genetic analyses. Those interviewed at the age of $53(n=3035)$ were, in most respects, representative of the national population of that age born in Britain (Wadsworth et al., 2003). Almost all participants ( $n=2,900,96 \%$ of the available sample) provided a blood sample. Ethical approval for this research was obtained from the North Thames Multi-Centre Research Ethics Committee and from relevant local research ethics committees in the survey areas. Informed consent was given by all the respondents. All analyses were performed using Mplus 7.4, with the WLSMV estimator and the theta parameterisation (Muthén and Muthén, 2015).

\section{Personality Trait Measures}

At ages 16 and 26 years, neuroticism and extraversion were assessed with six questions for each trait using the short from of the Maudsley Personality Inventory (MPI; Eysenck, 1958). All items had a binary "yes" (1) or "no" (0) response category.

\section{SNP Selection and Genotyping}

DNA was extracted and purified from whole blood using the Puregene DNA Isolation Kit (Flowgen, Leicestershire, UK) according to the manufacturer's protocol. The three MAOA SNPs, rs3788862, rs5906957, and rs979606 (Table 1), were typed using the KASPar system by KBioscience, UK (www.kbioscience. co.uk). These SNPs were selected using a Tagger implementation of the Haploview programme 9 (Barrett et al., 2005) to provide adequate coverage of the MAOA gene region. Two of these SNPs (rs979606 and rs3788862), or other SNPs mentioned earlier that are in high/complete LD with them, have been previously reported to be associated with MAOA functional activity (Hsu et al., 1995; Jansson et al., 2005).

For SNPs rs3788862 and rs5906957, in males A allele (the minor allele) was coded as 0 and $\mathrm{G}$ allele as 1 ; in females genotype
AA was coded as 0, AG as 1, and GG as 2. For SNP rs979606, in males $\mathrm{G}$ allele (the minor allele) was coded as 0 and $\mathrm{A}$ allele as 1 ; in females genotype GG was coded as $0, A G$ as 1 , and AA as 2. The three SNPs were used as binary (in males) or ordinal (in females) indicator variables for psychometrically modeling the latent genetic variable (Table 2). As such, positive factor loadings indicate the number of minor allele SNP contributed positively to the latent genetic factor whereas a negative factor loading indicate a negative direction.

\section{Statistical Analysis}

The main analysis was based on a sample with complete genetic information, and at least one non-missing personality item at both ages. We first used longitudinal measurement invariance analyses to assess the measurement properties of the repeated personality measures. Then, the cross-sectional and longitudinal $M A O A$ genetic effects on latent personality phenotypes were estimated using Structural Equation Models (SEM). For the cross-sectional analysis, MAOA latent genetic variable was specified to be a predictor of the latent variables representing personality traits (see Figure 1, cross-sectional model). For the longitudinal analysis, $M A O A$ latent genetic variable was specified to be a predictor of the change in neuroticism and extraversion respectively (see Figure 1, longitudinal model).

\section{Longitudinal Measurement Invariance Analyses}

Longitudinal measurement invariance analyses (Millsap, 2010) were conducted for the repeated dichotomous ratings of extraversion and neuroticism items in three steps: configural invariance (estimation of the same measurement model, with no added equality constraints), strong invariance (assessing the equality of factor loadings and item thresholds, which cannot be separated with binary rating scales) and strict invariance (assessing equality of factor loadings, item thresholds and residual variances). The goodness-of-fit of the models was evaluated using model fit indices. Since the chi-square is highly sensitive to sample size (Marsh et al., 1988, 2005), goodness of fit indices less sensitive to sample-size were also examined: the Root Mean Square Error of Approximation (RMSEA), the Tucker-Lewis Index (TLI), and the Comparative Fit Index (CFI; Fan et al., 1999; Hu and Bentler, 1999; Yu, 2002; Marsh et al., 2004). The TLI and CFI vary along a 0 -to- 1 continuum and values greater than 0.90 and 0.95 typically reflect an acceptable and excellent fit to the data. RMSEA values of less than 0.06 and 0.08 indicate a close fit and an acceptable fit to the data respectively. In terms of model comparisons for longitudinal measurement invariance analyses, a restrictive model is preferred if the change in model fit indices is not significantly inferior to those of the less restrictive model. For RMSEA, the change should be less than 0.015 (Chen, 2007). For CFI and TLI, the change should be less than 0.01 (Cheung and Rensvold, 2001; Chen, 2007). The chi-square difference tests compare the model under investigation to less restrictive alternative model and were computed with the DIFFTEST function for Mplus' robust weighted least square (WLSMV) estimator (Muthén and Muthén, 2015). 
TABLE 1 | Descriptive for MAOA SNPs allele, genotype and LD structure in males and females.

\begin{tabular}{|c|c|c|c|c|c|c|c|c|}
\hline \multirow[t]{2}{*}{ Snp } & \multirow[t]{2}{*}{ Chromosome location } & \multirow[t]{2}{*}{ Alleles (minor) } & \multicolumn{3}{|c|}{ MAF } & $n$ & MAF & $\begin{array}{c}\text { HWE } \\
p \text {-value }\end{array}$ \\
\hline & & & \multicolumn{3}{|c|}{ Males } & \multicolumn{3}{|c|}{ Females } \\
\hline rs3788862 & 43402308 & $\underline{A} / G$ & 1,240 & 0.300 & & 1,258 & 0.280 & 0.400 \\
\hline rs5906957 & 43432254 & $\underline{A} / G$ & 1,244 & 0.240 & & 1,260 & 0.220 & 0.870 \\
\hline \multirow[t]{4}{*}{ rs979606 } & 43486086 & $\underline{\mathrm{G}} / \mathrm{A}$ & 1,240 & 0.300 & & 1,257 & 0.290 & 0.130 \\
\hline & & & \multicolumn{6}{|c|}{ LD structure } \\
\hline & & & rs3788862 & rs5906957 & rs979606 & rs3788862 & rs5906957 & rs979606 \\
\hline & & & \multicolumn{3}{|c|}{ Males } & \multicolumn{3}{|c|}{ Females } \\
\hline rs3788862 & 43402308 & $\underline{A} / G$ & 1 & 0.680 & 0.750 & 1 & 0.700 & 0.790 \\
\hline rs5906957 & 43432254 & $\underline{A} / G$ & & 1 & 0.520 & & 1 & 0.560 \\
\hline rs979606 & 43486086 & $\mathrm{G} / \mathrm{A}$ & & & 1 & & & 1 \\
\hline
\end{tabular}

SNP, Single Nucleotide Polymorphisms; MAF, Minor allele frequency; HWE, Hardy-Weinberg equilibrium.

Since personality traits at ages 16 and 26 are repeated measures, we specified correlated residuals for the repeated items (McArdle, 2009).

\section{Latent Difference Scores Analyses}

In order to assess the effect of MAOA gene on personality changes between age 16 and age 26 , we derived factor scores of latent differences between age 16 and age 26 for extraversion and neuroticism, for males and females respectively. This is the longitudinal phenotype used in the current study and represents the change in personality from age 16 to age 26 (see Figure 1, longitudinal model). The use of latent different scores is valid in the circumstance that strong invariances are met as described in the previous section. This is because the calculation of latent differences scores requires estimation of factor means of repeated measures which is only meaningful when both factor loading and thresholds are invariant across both measurement occasions (McArdle and Prindle, 2008; McArdle, 2009). Technically in SEM framework, the latent difference score is represented by a latent variable that is obtained through regressing the time 2 latent variable on the time 1 latent variable, with the regression path set to 1 and the residual variances of the time 2 variable set to zero (see example Mplus syntax in Appendix). This way the time 2 variable is the sum of the time 1 variable and the latent change variable. In addition to the estimation of the variance of the latent difference score variable, latent mean of the change variable is also estimated, representing the increase/decrease of the latent variable since time 1 , whose mean is usually set to zero as a baseline of comparison. Parameters of latent difference scores obtained this way are free of measurement errors which typically severely plagues the reliability of simple difference scores obtained from observed measures (Thomas and Zumbo, 2012; Kisbu-Sakarya et al., 2013).

\section{Adjustment for Multiple Testing}

To control for multiple testing issues in the main analysis, we applied false discovery rate (FDR; Benjamini and Hochberg,
1995) and reported adjusted $p$-values along with uncorrected $p$-values for evaluating statistical significance threshold of the genetic association tests.

\section{Power Analysis}

We conducted both post hoc and a priori power analysis for the genetic latent variable predictor with statistically significant associations using statistical simulations. For post hoc power analysis, male sample size was fixed at 1,160 , the same as in the analytic sample. Population parameters were also fixed to be equal to the sample data of the corresponding latent genetic variable and phenotype. For each power analysis, 1000 replication data sets were generated and analyzed, with results averaged across the 1000 analysis. The a priori power analysis was carried out with similar parameterization as the crosssectional association model for extraversion at age 16 in males, for effect sizes with phenotypic variances explained at $1 \%, 2 \%$, and $3 \%$.

\section{RESULTS}

The descriptive statistics for the three MAOA SNPs is summarized in Table 1. All SNPs were in high linkage disequilibrium (LD), and with minor alleles exceeding frequency of $5 \%$. The integrity of genotyping was checked by genotyping frequency, concordance of duplicates and Hardy-Weinberg equilibrium (HWE). The call rates for the genotyped SNPs were $97.8-99.2 \%$, with $>95 \%$ concordance between duplicate samples, and there was no evidence of deviation from HWE (in females only, $p>0.05$ ). The MAOA latent variable was included in all subsequent analyses (factor loadings and genotype frequencies are presented in Table 2).

\section{Measurement Invariance Analysis of Longitudinal Phenotypes}

The personality phenotypes (see Table 2 for item descriptions) were first subject to tests of longitudinal measurement invariance. 
TABLE 2 | Descriptives and factor loadings for extraversion and neuroticism at ages 16 and 26 and MAOA SNPS.

\begin{tabular}{|c|c|c|c|c|c|c|c|c|c|}
\hline \multicolumn{5}{|c|}{ Male } & \multicolumn{5}{|c|}{ Female } \\
\hline & Yes & & No & & & Yes & & No & \\
\hline Loadings & $\%$ & Count & $\%$ & Count & Loadings & $\%$ & Count & $\%$ & Count \\
\hline
\end{tabular}

\begin{tabular}{|c|c|c|c|c|c|c|c|c|c|c|}
\hline \multicolumn{11}{|l|}{ EXTRAVERSION 16} \\
\hline $\begin{array}{l}\text { Are you happiest when you get involved in some project } \\
\text { which calls for rapid action? }\end{array}$ & 0.417 & 0.306 & 279 & 0.694 & 634 & 0.392 & 0.437 & 405 & 0.563 & 522 \\
\hline Do you usually take the initiative in making new friends? & 0.428 & 0.340 & 294 & 0.660 & 571 & 0.520 & 0.291 & 266 & 0.709 & 647 \\
\hline Are you inclined to be quick and sure in your actions? & 0.626 & 0.305 & 255 & 0.695 & 580 & 0.660 & 0.451 & 385 & 0.549 & 468 \\
\hline Would you rate yourself as a lively individual? & 0.689 & 0.172 & 151 & 0.828 & 727 & 0.742 & 0.218 & 193 & 0.782 & 692 \\
\hline $\begin{array}{l}\text { Would you be very unhappy if you were prevented from } \\
\text { making numerous social contacts? }\end{array}$ & 0.286 & 0.318 & 299 & 0.682 & 641 & 0.296 & 0.332 & 329 & 0.668 & 663 \\
\hline Do you prefer action to planning for action? & 0.239 & 0.321 & 287 & 0.679 & 608 & 0.284 & 0.358 & 335 & 0.642 & 602 \\
\hline \multicolumn{11}{|l|}{ NEUROTICISM 16} \\
\hline $\begin{array}{l}\text { Do you sometimes feel happy, sometimes depressed, } \\
\text { without any apparent reason? }\end{array}$ & 0.676 & 0.547 & 538 & 0.453 & 446 & 0.620 & 0.224 & 234 & 0.776 & 809 \\
\hline $\begin{array}{l}\text { Does your mind often wander while you are trying to } \\
\text { concentrate? }\end{array}$ & 0.520 & 0.456 & 452 & 0.544 & 539 & 0.571 & 0.355 & 365 & 0.645 & 664 \\
\hline $\begin{array}{l}\text { Are you frequently 'lost in thought' even when supposed } \\
\text { to be taking part in a conversation? }\end{array}$ & 0.518 & 0.712 & 694 & 0.288 & 281 & 0.576 & 0.637 & 649 & 0.363 & 370 \\
\hline $\begin{array}{l}\text { Are you sometimes bubbling over with energy and } \\
\text { sometimes very sluggish? }\end{array}$ & 0.571 & 0.494 & 476 & 0.506 & 487 & 0.549 & 0.340 & 344 & 0.660 & 668 \\
\hline Are you inclined to be moody? & 0.808 & 0.627 & 608 & 0.373 & 361 & 0.859 & 0.504 & 502 & 0.496 & 494 \\
\hline $\begin{array}{l}\text { Do you have frequent ups and downs in mood either with } \\
\text { or without apparent cause? }\end{array}$ & 0.879 & 0.649 & 628 & 0.351 & 340 & 0.885 & 0.427 & 430 & 0.573 & 576 \\
\hline \multicolumn{11}{|l|}{ EXTRAVERSION 26} \\
\hline $\begin{array}{l}\text { Are you happiest when you get involved in some project } \\
\text { that calls for rapid action? }\end{array}$ & 0.514 & 0.200 & 207 & 0.800 & 826 & 0.447 & 0.322 & 346 & 0.678 & 728 \\
\hline Do you usually take the initiative in making new friends? & 0.527 & 0.405 & 403 & 0.595 & 591 & 0.581 & 0.397 & 421 & 0.603 & 640 \\
\hline Are you inclined to be quick and sure in your actions? & 0.724 & 0.265 & 266 & 0.735 & 736 & 0.717 & 0.443 & 462 & 0.557 & 580 \\
\hline Would you rate yourself as a lively individual? & 0.779 & 0.232 & 233 & 0.768 & 770 & 0.792 & 0.256 & 261 & 0.744 & 759 \\
\hline $\begin{array}{l}\text { Would you be very unhappy if you were prevented from } \\
\text { making numerous social contacts? }\end{array}$ & 0.363 & 0.445 & 461 & 0.555 & 574 & 0.341 & 0.411 & 442 & 0.589 & 634 \\
\hline Do you prefer action to planning for action? & 0.306 & 0.318 & 313 & 0.682 & 672 & 0.328 & 0.342 & 351 & 0.658 & 676 \\
\hline \multicolumn{11}{|l|}{ NEUROTICISM 26} \\
\hline $\begin{array}{l}\text { Do you sometimes feel happy, sometimes depressed, } \\
\text { without any apparent reason? }\end{array}$ & 0.720 & 0.506 & 528 & 0.494 & 515 & 0.656 & 0.205 & 226 & 0.795 & 876 \\
\hline $\begin{array}{l}\text { Does your mind often wander while you are trying to } \\
\text { concentrate? }\end{array}$ & 0.568 & 0.521 & 546 & 0.479 & 501 & 0.608 & 0.361 & 397 & 0.639 & 704 \\
\hline $\begin{array}{l}\text { Are you frequently lost in thought even when supposed to } \\
\text { be taking part in a conversation? }\end{array}$ & 0.566 & 0.584 & 609 & 0.416 & 433 & 0.613 & 0.572 & 625 & 0.428 & 468 \\
\hline $\begin{array}{l}\text { Are you sometimes bubbling over with energy and } \\
\text { sometimes very sluggish? }\end{array}$ & 0.619 & 0.410 & 424 & 0.590 & 610 & 0.586 & 0.269 & 293 & 0.731 & 795 \\
\hline Are you inclined to be moody? & 0.841 & 0.596 & 613 & 0.404 & 415 & 0.879 & 0.538 & 586 & 0.462 & 504 \\
\hline Do you have frequent ups and downs in mood, either & 0.902 & 0.637 & 664 & 0.363 & 378 & 0.902 & 0.481 & 526 & 0.519 & 568 \\
\hline
\end{tabular}

with or without apparent cause?

Genotype A Genotype G

Genotype AA Genotype AG Genotype GG

\begin{tabular}{|c|c|c|c|c|}
\hline Loadings & & & $\%$ & \\
\hline
\end{tabular}

\section{MAOA LATENT GENETIC FACTOR}

RS3788862

RS5906957

0.989

0.989

$\begin{array}{llll}0.703 & 816 & 0.297 & 344\end{array}$

0.968

0.524

6180.392

462

0.085100

RS979606

$\begin{array}{lllll}0.984 & 0.699 & 811 & 0.301 & 349\end{array}$

$0.959-0.517-610$

$406 \quad 0.052$

$\begin{array}{lll}461 & 0.092 \quad 109\end{array}$

Factor loadings were standardized estimates based on a multiple group model with strict measurement invariance constraints (Table 3, models m3 for males and f3 for females).

Given that all measurement models included MAOA latent variables, these tests were conducted separately for males and females participants. In the configural model (Table 3, model $\mathrm{m} 1$ for males and model $\mathrm{f} 1$ for females), all factor loadings and thresholds were freely estimated with confirmatory factor analytic models. Results revealed that this model fitted the 


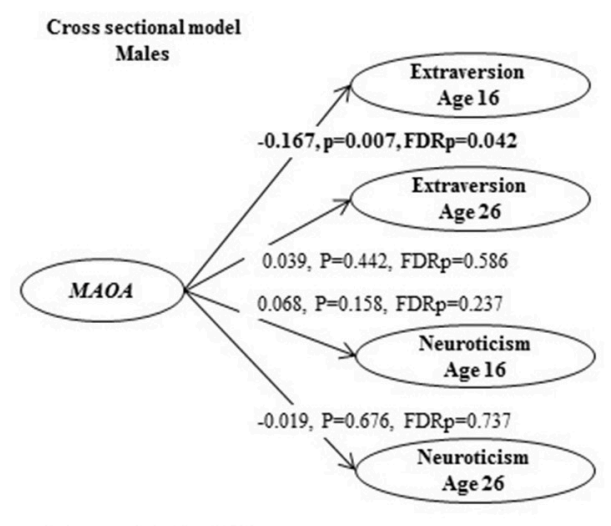

Cross sectional model Females

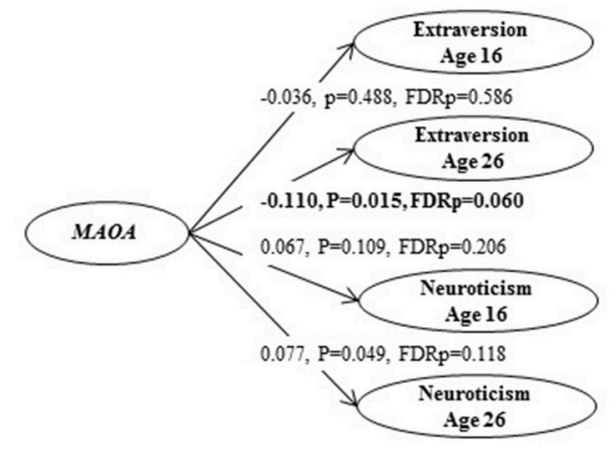

Longitudinal model

Males

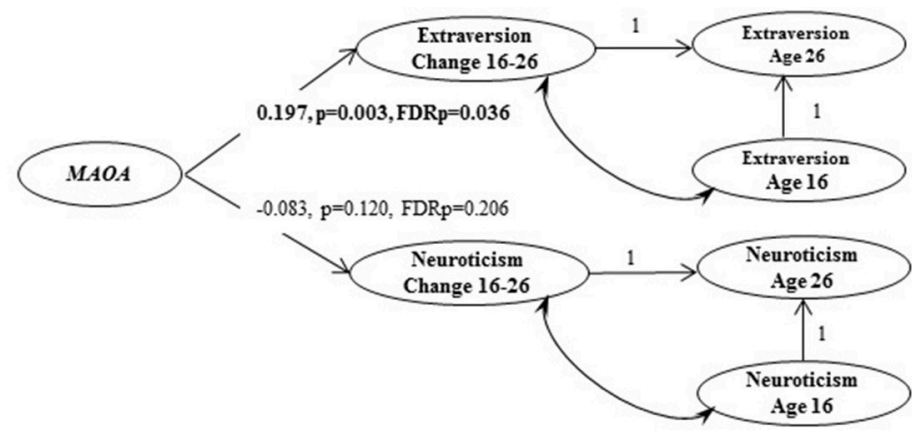

Longitudinal model

Females

FIGURE 1 | Cross-sectional and longitudinal models of genetic associations between MAOA and personality traits. Coefficients that are standardized bold values statistically significant at $P<0.05$, after adjusting for false discovery rate.

data very well. In the next model (model $\mathrm{m} 2$ for males and model $\mathrm{f} 2$ for females), both factor loadings and thresholds were constrained equal across time. Compared with the baseline model, changes in model fit indices remained minimal, thus supporting the strong longitudinal invariance of the model. In the third model (model $\mathrm{m} 3$ for males and model $\mathrm{f} 3$ for females), the residual variances of individual items were further constrained to equality across measurement waves. There were no changes in model fit indices for males, and there was even an improvement for females, supporting the strict measurement invariance of the personality measures across age 16 and 26, thus providing support for comparability of measurements across waves and further ground for using latent change scores.

Factor loadings of models $\mathrm{m} 3$ and $\mathrm{f} 3$ are presented in Table 2, whereas correlations and latent difference means estimated from models $\mathrm{m} 3$ and $\mathrm{f} 3$ are presented in Table 4 . In both male and female samples, strong correlations were observed between repeated extraversion ( 0.592 for males and 0.565 for females) and neuroticism ( 0.526 for males and 0.479 for males) factors, attesting to their stability over time. There were also weak to modest correlations between extraversion and neuroticism factors $(-0.077$ to -0.221 in males and -0.189 to -0.312 in females), attesting to their distinctiveness. Latent difference scores in extraversion and neuroticism were specified based on a re-parameterization of models $\mathrm{m} 3$ and $\mathrm{f} 3$. These latent difference factors are the longitudinal phenotypes used in genetic association analysis (Figure 1). The estimated means of the latent change scores were not statistically different from zero among the male and female samples (Table 4). However, the variances of the change scores were statistically significant, implying the presence of meaningful inter-individual variations in the change scores estimated for both samples.

\section{Genetic Association Analysis of Cross-Sectional and Longitudinal Phenotypes}

Genetic association analyses were performed with the MAOA latent variable as a predictor in cross-sectional and longitudinal models of extraversion and neuroticism. SEM analyses demonstrated an association of the MAOA latent genetic variable $(A A G)$ with lower extraversion scores at age 16 in males (Figure 1, $\beta=-0.167, \mathrm{FDRp}=0.042$ ). The MAOA latent genetic variable was also positively associated with change in extraversion in males $(\beta=0.197, \mathrm{FDRp}=0.036$, see an example syntax in Appendix). No statistically significant associations 
TABLE 3 | Model fit indices for the measurement invariance analyses of longitudinal phenotypes of personality traits and genetic association tests.

\begin{tabular}{|c|c|c|c|c|c|c|c|c|c|c|c|}
\hline & model & $n$ & $x^{2}$ & $\begin{array}{l}\text { degree of } \\
\text { freedom }\end{array}$ & $\begin{array}{c}\text { free } \\
\text { parameter }\end{array}$ & $\begin{array}{l}\text { Model of } \\
\text { comparison }\end{array}$ & $\begin{array}{c}\text { x2 Difference } \\
\text { Test }\end{array}$ & $\begin{array}{l}p \text { (degree of } \\
\text { freedom) }\end{array}$ & RMSEA & CFI & TLI \\
\hline \multicolumn{12}{|l|}{ MALES } \\
\hline Strong invariance & m2 & 1,160 & 878.578 & 311 & 67 & $\mathrm{~m} 1$ & 83.215 & $<0.001(8)$ & 0.040 & 0.989 & 0.988 \\
\hline Strict invariance & m3 & 1,160 & 935.975 & 254 & 55 & m2 & 63.882 & $<0.001(12)$ & 0.040 & 0.989 & 0.988 \\
\hline \multicolumn{12}{|l|}{ FEMALES } \\
\hline Configural model & $f 1$ & 1,180 & $1,054.311$ & 303 & 78 & & & & 0.046 & 0.986 & 0.984 \\
\hline Strong invariance & $\mathrm{f} 2$ & 1,180 & 1,116.822 & 311 & 70 & f1 & 73.142 & $<0.001(8)$ & 0.047 & 0.985 & 0.983 \\
\hline Strict invariance & f3 & 1,180 & $1,133.666$ & 323 & 58 & f2 & 32.860 & $<0.001(12)$ & 0.046 & 0.985 & 0.984 \\
\hline SEM cross-sectional & f4 & 1,180 & $1,041.822$ & 313 & 68 & & & & 0.044 & 0.987 & 0.985 \\
\hline
\end{tabular}

RMSEA, Root Mean Square Error of Approximation; CFI, Comparative Fit Index; TLI, Tucker-Lewis Index.

TABLE 4 | Factor means and correlations of extraversion and neuroticism in males (model m3) and females (model f3).

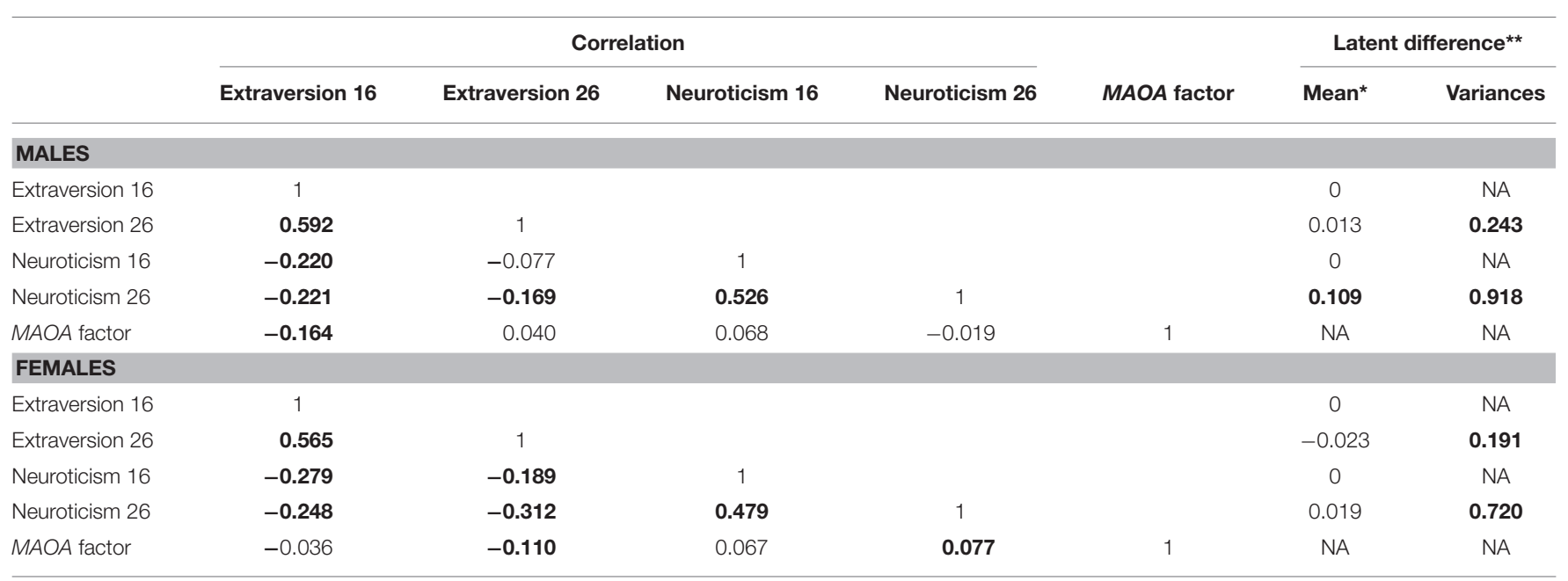

Bold values are statistically significant at $P<0.05$.

${ }^{\star}$ Means are based on original latent factor scales.

${ }^{*}$ Latent difference model is an identical model with alternative parameterization of the cross-sectional model ( $\left.m 3, f 3\right)$.

between the MAOA gene and personality traits were found in females after multiple testing adjustment.

In an additional sensitivity analysis for the male participants, $M A O A$ factor scores were calculated and categorized into high and low values groups, representing the top $30 \%$ and bottom $30 \%$ of the genetic scores respectively. Results from the additional analysis on this subsample $(n=695)$ showed larger effect sizes for both the association with age 16 extraversion $(\beta=-0.264$, $p<0.001)$, and the change in extraversion from age 16 to age 26 $(\beta=0.275, p<0.001)$.

\section{Power Analysis}

To assess the statistical power of the analyses conducted in the male sample, Monte Carlo simulation analysis was performed both for our latent genetic approach and the traditional single SNP approach (Table 5). The latent genetic approach has a power of $81.2 \%$ for an effect size of $2.8 \%$ as observed in empirical cross-sectional association with extraversion at age 16 . The power is $88.8 \%$ for an effect size of $3.9 \%$ as observed empirically for the change in extraversion from age 16 to age 26.

We additionally conducted a priori power analysis with similar parameterization as the cross-sectional association model for extraversion at 16 in males, for effect sizes with phenotypic variances explained at $1 \%, 2 \%$, and $3 \%$. For $1 \%$ phenotypic variance explained, the resulted power was 0.55 based on latent genetic approach and 0.41 for the corresponding single SNP approach (with an effect size of $0.7 \%$ ). For $2 \%$ phenotypic variance explained, the resulted power was 0.84 based on latent genetic approach and 0.71 for the corresponding single SNP approach (with an effect size of $1.2 \%)$. For $3 \%$ phenotypic variance explained, the resulted power was 0.95 based on latent genetic approach and 0.87 for 
TABLE 5 | Power analysis of latent genetic variable and single SNP approaches for SNPs with significant genetic effect in the male sample.

\begin{tabular}{lcccc}
\hline Method & $\begin{array}{c}\text { Latent gene } \\
\text { approach }\end{array}$ & \multicolumn{3}{c}{ Single SNP approach } \\
\cline { 3 - 5 } & & rs3788862 & rs5906957 & rs979606 \\
\hline CROSS-SECTIONAL ASSOCIATION WITH EXTRAVERSION AT AGE 16 & $1.7 \%$ & $1.5 \%$ \\
Effect size & $2.8 \%$ & $78.6 \%$ & $74.5 \%$ & $78.9 \%$ \\
Power & $81.2 \%$ & $1.8 \%$ & $1.4 \%$ & $2.5 \%$ \\
CHANGE IN EXTRAVERSION & FROM AGE & $\mathbf{1 6}$ & TO AGE 26 \\
Effect size & $3.9 \%$ & $85.8 \%$ & $84.2 \%$ & $87.8 \%$ \\
Power & $88.8 \%$ & & & \\
\hline
\end{tabular}

Effect size is based on percentage of explained phenotype variances by a single SNP predictor (i.e., the square of standardized regression coefficient in the case of a single predictor). Power statistic is based on 1,000 simulated replications; sample size was fixed at 1,160 consistent with the current male sample.

the corresponding single SNP approach (with an effect size of $1.6 \%)$.

Both the post hoc and a priori power analysis have shown higher power in latent genetic approach compared to those found from single SNP approach, which will be even smaller once multiple testing corrections are applied for all three SNPs.

\section{DISCUSSION}

The association of the MAOA gene based on a latent genetic variable of three SNPs was investigated in relation to cross-sectional and longitudinal psychometric phenotypes of neuroticism and extraversion in a population-based study. The results revealed age-specific effects in males. In males, the $M A O A$ latent genetic factor was associated with extraversion at age 16 and with the change scores in extraversion from 16 to 26 years.

Our findings for extraversion are in line with some previous studies of personality phenotypes. For example, the MAOA uVNTR is associated with Harm Avoidance (Yu et al., 2005), Persistence (Tsuchimine et al., 2008), Novelty Seeking and Reward Dependence (Shiraishi et al., 2006). Our study suggests that the three SNPs in the current investigation might function in similar fashion in terms of association with personality traits.

Another MAOA polymorphism, rs6323, located in exon 8 has a functional effect on mRNA level in the brain, with $\mathrm{T}$ allele associated with higher level and $\mathrm{G}$ allele with lower level of MAOA expression (Pinsonneault et al., 2006). One of our SNPs, rs979606, is in complete LD with rs6323, and the $G$ allele of rs979606 is correspondent to the $G$ allele of rs6323. As part of the latent genetic variable, the $G$ allele of rs979606 was associated with lower extraversion scores in males in our study at age 16. This is in agreement with several studies suggesting that a MAOA variant with higher level of expression is associated with higher level of Novelty Seeking (Shiraishi et al., 2006), a phenotype closely related to extraversion (Zuckerman and Cloninger, 1996; De Fruyt et al., 2000; Livesley, 2001).

In general, the current study provides further evidence for the role of the MAOA gene in personality, and extraversion in particular. These genetic effects on extraversion may be underpinned by individual differences in brain structure and function. For instance, extraverts have more blood flow in the anterior cingulate gyrus, temporal lobes, and posterior thalamus, which are involved in sensory and emotional experience (Johnson et al., 1999) and can be affected by the MAOA genotype (Meyer-Lindenberg et al., 2006; Cerasa et al., 2010).

Our study showed more marked MAOA effect on extraversion in males than in females, indicating sex-specific association between the MAOA gene and personality (Deckert et al., 1999; Herman et al., 2005; Biederman et al., 2008). Genetic variants in the X-located MAOA gene may have different effects on cognition and behavior in males and females, and may explain sex differences in incidence and prevalence of certain psychopathologies. Indeed, several studies have found that various polymorphic variants in the MAOA gene (a 30-bp variable-number tandem repeat polymorphism in the promoter region; a GA repeat polymorphism in intron 2; and a G/T singlenucleotide polymorphism in exon 8) are associated with ADHD, ASD, and antisocial behavior, which have higher prevalence in men than in women (Karayiorgou et al., 1999; Huang et al., 2004). Furthermore, epigenetic regulatory mechanisms, such as methylation (Pinsonneault et al., 2006; Checknita et al., 2015) and incomplete $\mathrm{X}$ inactivation (Carrel and Willard, 2005), as well as regulation by Y-encoded transcription factor SRY (Wu et al., 2009) could contribute to sex differences of MAOA-related psychiatric disorders. These observed sex-specific associations might reflect sex differences in brain structure and function (Giedd et al., 1999; Cahill, 2009), but could also be due to uncertainties in the exact mechanisms as a result of $\mathrm{X}$ inactivation. For instance, one study found that the low expressed $M A O A$ variant, associated with increased risk of violent behavior, was associated with changes in orbitofrontal volume, amygdala and hippocampus hyper-reactivity during aversive recall, and impaired cingulate activation during cognitive inhibition in men only (Meyer-Lindenberg et al., 2006). Nevertheless, it important that these results are interpreted with caution before the pathways of $\mathrm{X}$ inactivation are more thoroughly understood.

Our findings suggest that age is an important factor for effects of the MAOA gene on personality. In males, the MAOA gene was associated with extraversion at age 16 , and with longitudinal change in extraversion between ages 16 and 26. This finding is consistent with other studies that suggest the dynamic nature of genetic effects. For example, it is known that genetic effects on some complex traits become stronger from childhood through adolescence and adulthood (e.g., Haworth et al., 2010; Gaysina et al., 2013). One of the plausible mechanisms of agespecific effects of genetic variants is the related changes in the gene expression (Francesconi and Lehner, 2014). It has been demonstrated that expression activity of many brain-expressed genes, including $M A O A$ gene, can change during development and maturation both in human and animals (Vitalis et al., 2002; Naumova et al., 2013; Bakken et al., 2016). However, we should note that the evidence for the mechanisms of developmentspecific effects of MAOA remains limited. The data available on specific development stages refer mainly to the mammal brain at fetal and post-fetal stages (for review, see Nicotra et al., 2004). For example, one study used in situ hybridization and histochemistry to localize MAOA (and MAOB) in the developing nervous system of mice. This study found that during postnatal life, MAOA expression declines (Vitalis et al., 2002). 
It is known that many developmental changes occur between ages 16 and 26 years, and young people are exposed to various influences from many environmental factors. Therefore, we cannot exclude possible gene-environment interactions effects on personality during the transition to adulthood. For example, several studies have reported an interaction between the MAOA gene and childhood stress on conduct and antisocial disorders, that is stronger in males (Kim-Cohen et al., 2006; Taylor and Kim-Cohen, 2007; Holz et al., 2014; Ouellet-Morin et al., 2016; Zhang et al., 2016). It may be the case that there are other environmental factors, such as significant life events, which interact with the MAOA gene and influence personality traits. This phenomenon may explain why genetic effects differ across the life course.

The present has a number of strengths and limitations. While most studies of MAOA gene effects on personality used small, cross-sectional samples, the present study has the advantage of using a population-based, longitudinal sample spanning from late adolescence to early adulthood. This developmental approach is of particular importance for studying the dynamic nature of genetic effects.

The application of latent variable methods is appropriate for modeling both the genetic variants and the phenotypes under investigation. Latent genotypic variables have previously been shown to be an effective way to capture genetic variances from multiple SNPs (Smyrnis et al., 2009; Tsonaka et al., 2012; Bentley et al., 2013). This approach summarizes genotypic information across all genetic variants studied and capturing potential correlations between them. Thus, the power of detecting genetic effects can be elevated compared with separate SNP testing which ignores this feature. The strengths and potential of this method in even larger sets of SNPs have been evaluated across several settings in Tsonaka et al. (2012). Genetic effects found in association studies of complex traits such as personality are usually small due to influences from multiple genes (Plomin et al., 1994), and gene-gene, gene-environment interactions (Mackay, 2001). Phenotypic measurement error is a possible contributor to inconsistent findings by attenuating the effect sizes (McCoach et al., 2007) and reducing statistical power to detect the genetic association with phenotypes (van der Sluis et al., 2010). The latent variable approach we applied is an effective approach to improve phenotype definitions (Smyrnis et al., 2009; Ducci et al., 2010; Gaysina et al., 2013; Xu et al., 2015).

Therefore, the methodological strength of the present study lies in the use of the latent variable approach which has several appealing features over other commonly applied methods. In particular, the analysis for each SNP separately is less powerful (as shown in both a priori and the post hoc power analysis) than the currently implemented latent variable method, because in single SNP analysis the number of tests depends on the number of SNPs in the gene-set of interest. Therefore, the multiple testing correction burden is greater. On the contrary, the latent variable method summarizes the genetic information from the SNPs via a single latent variable, therefore only a single test is implemented irrespective of the number of SNPs considered.

Another common practice used in studying multiple SNPs is the construction of polygenic scores. Although, this approach is computationally simpler (a sum of the SNPs weighted by the marginal effects of the SNPs on the phenotype) and easy to implement in practice, the polygenic score has two important limitations. First, it requires a priori knowledge of the separate SNP effects. Second, for its computation the sampling variability (i.e., standard error) of the separate SNP effects is ignored. This implies that the effects of the polygenic score will be inevitably attenuated (i.e., biased). This phenomenon has been thoroughly studied in the measurement error literature (e.g., Carroll et al., 2006). Our approach instead properly accounts for this sampling variability and does not require prior knowledge for the separate SNP effects as it provides an empirically derived optimal weighting of the different SNP scores.

The latent variable approach also provides stronger statistical power to detect statistically significant effects. The type I error and power of the latent variable approach have been thoroughly investigated empirically in the study of Tsonaka et al. (2012) where longitudinal genetic effects were studied. In this study, several scenarios were considered regarding the between-SNPs correlation structure (i.e., low vs. moderate correlation) including the size of the association of the subjects' genotypes with the phenotype, and size of the gene-set and sample size. The sample sizes considered there were much smaller than in the current study but the latent variable approach still achieves high and satisfactory levels of power while preserving the type I error at nominal level.

Furthermore, as shown in the additional simulation power analysis performed for the current study, the latent genetic approach demonstrated consistently higher statistical power compared to single SNP approach, even before applying corrections for multiple testing. Moreover, when analysing all the SNPs simultaneously in the same model, we explicitly took advantage of the potential correlations among SNPs. Both positive and negative correlations between the SNPs are allowed, while this correlation is totally ignored in the separate SNP tests. Although post hoc power analysis showed sufficient to high statistical power for the effect sizes observed in the current study, this is partly due to effect sizes which were relatively high compared to previous GWAS studies on gene based analysis (Luciano et al., 2017) or polygenic risk scores (van den Berg et al., 2016). The a priori power analysis showed that for studies with sample sizes comparable to the present investigation $(n=1,160)$, although the power $(0.84)$ is sufficient for detecting variances explained at $2 \%$, for effect size of $1 \%$ variance explained, the power drops to 0.41 . Therefore, it is important to ensure the study is of sufficient sample size to detect expected effect sizes with sufficient power.

In terms of limitations, we did not formally test for population stratification, however all participants in the current study were of white Caucasian background, so the population stratification is unlikely. We did not take into account environmental exposures, whereas genetic factors and known to interact with environmental factors in their influences on complex traits. Similarly, in the current study, we did not have functional indicators (e.g., sex hormone levels) to test for effect modification that could correspond with developmental stages. Moreover, as 
already mentioned previously, our results in females need to be interpreted with caution. It is known that many X-chromosome genes may express differently in males and females, due to incomplete inactivation of one of two X chromosomes in females, as well as other mechanisms (as discussed above). In our study, information on the status of X-chromosome inactivation was not available. Future studies which incorporate such information would be very helpful in order to further clarify and determine the role of MAOA gene in personality traits. Furthermore, replications based on large studies are needed to confirm the effects observed in the male sample of the present study. As such, future GWAS studies could include genes on X chromosome both in male samples and in female samples for putative genetic associations.

In conclusion, the present study confirms that $M A O A$ genetic variation affects personality traits in age-specific manner in males. Our study highlights the importance of applying a life course developmental approach to behavioral genetics (Scerif and Karmiloff-Smith, 2005). This is particularly important for candidate genes, such as MAOA, which is widely thought to interact with environmental factors to influence behavioral outcomes across developmental stages (Kim-Cohen et al., 2006). Future studies exploring the gene-environmental interaction in longitudinal design such as our study are likely to help clarify the role $M A O A$ gene plays in the crafting of personality.

\section{AUTHOR CONTRIBUTIONS}

MX, DG, and PJ designed the study, MX conducted analysis, MX and DG wrote up the manuscript; RT and JH contributed

\section{REFERENCES}

Arai, R., Kimura, H., Nagatsu, I., and Maeda, T. (1997). Preferential localization of monoamine oxidase type A activity in neurons of the locus coeruleus and type B activity in neurons of the dorsal raphe nucleus of the rat: a detailed enzyme histochemical study. Brain Res.745, 352-356. doi: 10.1016/S0006-8993(96)01239-5

Bakken, T. E., Miller, J. A., Ding, S. L., Sunkin, S. M., Smith, K. A., Ng, L., et al. (2016). Comprehensive transcriptional map of primate brain development. Nature 535:367. doi: 10.1038/nature18637

Barrett, J. C., Fry, B., Maller, J., and Daly, M. J. (2005). Haploview: analysis and visualization of LD and haplotype maps. Bioinformatics 21, 263-265. doi: 10.1093/bioinformatics/bth457

Benjamin, J., Ebstein, R. P., and Belmaker, R. H. (2008). Molecular Genetics and the Human Personality. Washington, DC: American Psychiatric Publishing.

Benjamini, Y., and Hochberg, Y. (1995). Controlling the false discovery rate: a practical and powerful approach to multiple testing. J. R. Stat. Soc. B 57, 289-300.

Bentley, M. J., Lin, H., Fernandez, T. V., Lee, M., Yrigollen, C. M., Pakstis, A. J., et al. (2013). Gene variants associated with antisocial behaviour: a latent variable approach. J. Child Psychol. Psychiatry 54, 1074-1085. doi: $10.1111 /$ jcpp.12109

Berletch, J. B., Yang, F., Xu, J., Carrel, L., and Disteche, C. M. (2011). Genes that escape from X inactivation. Hum. Genet. 130, 237-245. doi: 10.1007/s00439-011-1011-z

Biederman, J., Kim, J. W., Doyle, A. E., Mick, E., Fagerness, J., Smoller, J. W., et al. (2008). Sexually dimorphic effects of four genes (COMT, SLC6A2, MAOA, SLC6A4) in genetic associations of ADHD: a preliminary study. Am. J. Med. Genet. B. 147B, 1511-1518. doi: 10.1002/ajmg. b. 30874 to the design of genotypic modeling; AM and TC contributed to design of phenotypic modeling. All authors contributed to the formulation of the study in its current form and improved iterative versions of the manuscript. All authors agree to be accountable for all aspects of the study and give final approval of the version to be published.

\section{FUNDING}

This work was supported by the Wellcome Trust grant (MX, DG, TC, MR, and PJ; grant number 088869/Z/09/Z), and grant MIMOmics of the European Union's Seventh Framework Programme FP7-Health-F5- 2012 (MX, RT, and JH; grant number 305280). PJ acknowledges financial support from the NIHR CLAHRC East of England. MR is supported by the Medical Research Council (grant code MC_UU_12019/3, MC_UU_12019/1). We would like to acknowledge the Swallow group, UCL, who performed the DNA extractions (Rousseau et al., 2006; https://doi.org/10.5522/NSHD/Q101).

\section{ACKNOWLEDGMENTS}

The authors thank all study members of NSHD, and NSHD scientific and data collection teams.

\section{SUPPLEMENTARY MATERIAL}

The Supplementary Material for this article can be found online at: https://www.frontiersin.org/articles/10.3389/fpsyg. 2017.01736/full\#supplementary-material

Bleidorn, W., Kandler, C., Riemann, R., Spinath, F. M., and Angleitner, A. (2009). Patterns and sources of adult personality development: growth curve analyses of the NEO PI-R scales in a longitudinal twin study. J. Pers. Soc. Psychol. 97, 142-155. doi: 10.1037/a0015434

Bortolato, M., Godar, S. C., Alzghoul, L., Zhang, J., Darling, R. D., Simpson, K. L. et al. (2013). Monoamine oxidase A and A/B knockout mice display autistic-like features. Int. J. Neuropsychopharmacol. 16, 869-888. doi: $10.1017 /$ S1461145712000715

Bouchard, T. J., and Loehlin, J. C. (2001). Genes, evolution, and personality. Behav. Genet. 31, 243-273. doi: 10.1023/A:1012294324713

Breakefield, X. O., Giller, E. L., Nurnberger, J. I., Castiglione, C. M., Buchsbaum, M. S., and Gershon, E. S. (1980). Monoamine oxidase type A in fibroblasts from patients with bipolar depressive illness. Psychiatry Res. 2, 307-314. doi: 10.1016/0165-1781(80)90022-0

Cahill, L. (2009). His brain, her brain. Spec. Edn. 20, 40-47. doi: 10.1038 /scientificamericanmind0509-40

Carrel, L., and Willard, H. F. (2005). X-inactivation profile reveals extensive variability in X-linked gene expression in females. Nature 434, 400-404. doi: $10.1038 /$ nature03479

Carroll, R. J., Ruppert, D., Stefanski, L. A., and Crainiceanu, C. M. (2006). Measurement Error in Nonlinear Models: A Modern Perspective. Boca Raton, FL: CRC press.

Cerasa, A., Cherubini, A., Quattrone, A., Gioia, M. C., Magariello, A., Muglia, M. et al. (2010). Morphological correlates of MAO A VNTR polymorphism: new evidence from cortical thickness measurement. Behav. Brain Res. 211, 118-124. doi: 10.1016/j.bbr.2010.03.021

Checknita, D., Maussion, G., Labonté, B., Comai, S., Tremblay, R., Vitaro, F. et al. (2015). Monoamine oxidase A gene promoter methylation and transcriptional downregulation in an offender population with antisocial personality disorder. Br. J. Psychiatry 206, 216-222. doi: 10.1192/bjp.bp.114.144964 
Chen, F. F. (2007). Sensitivity of goodness of fit indexes to lack of measurement invariance. Struct. Equat. Model. 14, 464-504. doi: 10.1080/10705510701301834

Cheung, G. W., and Rensvold, R. B. (2001). The effects of model parsimony and sampling error on the fit of structural equation models. Organ. Res. Methods 4, 236-264. doi: 10.1177/109442810143004

De Fruyt, F., De Wiele, L. V., and Van Heeringen, C. (2000). Cloninger's psychobiological model of temperament and character and the Five-Factor Model of personality. Pers. Individ. Dif. 29, 441-452 .doi: 10.1016/S0191-8869(99)00204-4

de Moor, M. H., van den Berg, S. M., Verweij, K. J., Krueger, R. F., Luciano, M., Vasquez, A. A. et al. (2015). Genome-wide association study identifies novel locus for neuroticism and shows polygenic association with major depressive disorder. JAMA Psychiatry 72:642. doi: 10.1001/jamapsychiatry.2015.0554

Deckert, J., Catalano, M., Syagailo, Y. V., Bosi, M., Okladnova, O., Di Bella, D., et al. (1999). Excess of high activity monoamine oxidase A gene promoter alleles in female patients with panic disorder. Hum. Mol. Genet. 8, 621-624. doi: $10.1093 / \mathrm{hmg} / 8.4 .621$

Distel, M. A., Trull, T. J., Willemsen, G., Vink, J. M., Derom, C. A., Lynskey, M., et al. (2009). The five-factor model of personality and borderline personality disorder: a genetic analysis of comorbidity. Biol. Psychiatry 66, 1131-1138. doi: 10.1016/j.biopsych.2009.07.017

Ducci, F., Kaakinen, M., Pouta, A., Hartikainen, A. L., Veijola, J., Isohanni, M., et al. (2010). TTC12-ANKK1-DRD2 and CHRNA5-CHRNA3-CHRNB4 Influence different pathways leading to smoking behavior from adolescence to midadulthood. Biol. Psychiatry 69, 650-660. doi: 10.1016/j.biopsych.2010.09.055

Ducci, F., Newman, T. K., Funt, S., Brown, G. L., Virkkunen, M., and Goldman, D. (2006). A functional polymorphism in the MAOA gene promoter (MAOALPR) predicts central dopamine function and body mass index. Mol. Psychiatry 11:858. doi: 10.1038/sj.mp.4001856

Ebstein, R. P. (2006). The molecular genetic architecture of human personality: beyond self-report questionnaires. Mol. Psychiatry 11, 427-445. doi: 10.1038/sj.mp.4001814

Eley, T. C., Tahir, E., Angleitner, A., Harriss, K., McClay, J., Plomin, R. et al. (2003). Association analysis of MAOA and COMT with neuroticism assessed by peers. Am. J. Med. Genet. B. 120B, 90-96. doi: 10.1002/ajmg.b.20046

Enoch, M. A., Steer, C. D., Newman, T. K., Gibson, N., and Goldman, D. (2010). Early life stress, MAOA, and gene environment interactions predict behavioral disinhibition in children. Genes, Brain Behav. 9, 65-74. doi: 10.1111/j.1601-183X.2009.00535.x

Eysenck, H. J. (1958). A short questionnaire for the measurement of two dimensions of personality. J. Appl. Psychol. 42, 14-17. doi: 10.1037/h0041738

Fan, X., Thompson, B., and Wang, L. (1999). Effects of sample size, estimation methods, and model specification on structural equation modeling fit indexes. Struct. Equat. Model. 6, 56-83. doi: 10.1080/10705519909540a119

Fergusson, D. M., Boden, J. M., Horwood, L. J., Miller, A. L., and Kennedy, M. A. (2011). MAOA, abuse exposure and antisocial behaviour: 30-year longitudinal study. Br. J. Psychiatry 198, 457-463. doi: 10.1192/bjp.bp.110.086991

Foster, J. A., and MacQueen, G. (2008). Neurobiological factors linking personality traits and major depression. Can. J. Psychiatry 53, 6-13. doi: $10.1177 / 070674370805300103$

Francesconi, M., and Lehner, B. (2014). The effects of genetic variation on gene expression dynamics during development. Nature 505:208. doi: 10.1038/nature12772

Gale, C., Hagenaars, S. P., Davies, G., Hill, W. D., Liewald, D. C., Cullen, B., et al. (2016). Pleiotropy between neuroticism and physical and mental health: findings from 108038 men and women in UK Biobank. Transl. Psychiatry 6:e791. doi: $10.1038 /$ tp. 2016.56

Gaysina, D., Xu, M. K., Barnett, J. H., Croudace, T. J., Wong, A., Richards, M. et al. (2013). The catechol-O-methyltransferase gene (COMT) and cognitive function from childhood through adolescence. Biol. Psychol. 92, 359-364. doi: 10.1016/j.biopsycho.2012.11.007

Giedd, J. N., Blumenthal, J., Jeffries, N. O., Castellanos, F. X., Liu, H., Zijdenbos, A., et al. (1999). Brain development during childhood and adolescence: a longitudinal MRI study. Nat. Neurosci. 2, 861-862. doi: 10.1038/13158

Haworth, C. M., Wright, M. J., Luciano, M., Martin, N. G., de Geus, E. J., Van Beijsterveldt, C. E., et al. (2010). The heritability of general cognitive ability increases linearly from childhood to young adulthood. Mol. Psychiatry 15:1112. doi: $10.1038 / \mathrm{mp} .2009 .55$
Herman, A. I., Kaiss, K. M., Ma, R., Philbeck, J. W., Hasan, A., Dasti, H., et al. (2005). Serotonin transporter promoter polymorphism and monoamine oxidase type A VNTR allelic variants together influence alcohol binge drinking risk in young women. Am. J. Med. Genet. B 133B, 74-78. doi: 10.1002/ajmg.b.30135

Holz, N., Boecker, R., Buchmann, A. F., Blomeyer, D., Baumeister, S., Hohmann, S., et al. (2014). Evidence for a sex-dependent MAOA $\times$ childhood stress interaction in the neural circuitry of aggression. Cereb. Cortex 26, 904-914. doi: 10.1093/cercor/bhu249

Hotamisligil, G. S., and Breakefield, X. O. (1991). Human monoamine oxidase A gene determines levels of enzyme activity. Am. J. Human Genet. 49, 383-392.

Hsu, Y. P., Schuback, D. E., Tivol, E. A., Shalish, C., Murphy, D. L., and Breakefield, X. O. (1995). Analysis of MAOA mutations in humans. Prog. Brain Res. 106, 67-75. doi: 10.1016/S0079-6123(08)61203-0

Hu, L., and Bentler, P. M. (1999). Cutoff criteria for fit indexes in covariance structure analysis: conventional criteria versus new alternatives. Struct. Equat. Model. 6, 1-55. doi: 10.1080/107055199095 40118

Huang, Y. Y., Cate, S. P., Battistuzzi, C., Oquendo, M. A., Brent, D., and Mann, J. J. (2004). An association between a functional polymorphism in the monoamine oxidase a gene promoter, impulsive traits and early abuse experiences. Neuropsychopharmacol. 29, 1498-1505. doi: 10.1038/sj.npp.1300455

Jansson, M., McCarthy, S., Sullivan, P. F., Dickman, P., Andersson, B., Oreland, L. et al. (2005). MAOA haplotypes associated with thrombocyte-MAO activity. BMC Genet. 6:46. doi: 10.1186/1471-2156-6-46

Johnson, D. L., Wiebe, J. S., Gold, S. M., Andreasen, N. C., Hichwa, R. D., Watkins, G. L. et al. (1999). Cerebral blood flow and personality: a positron emission tomography study. Am. J. Psychiatry 156, 252-257.

Jorm, A. F., Henderson, A. S., Jacomb, P. A., Christensen, H., Korten, A. E., Rodgers, B., et al. (2000). Association of a functional polymorphism of the monoamine oxidase A gene promoter with personality and psychiatric symptoms. Psychiatr. Genet. 10:87. doi: 10.1097/00041444-200010020-00006

Jorm, A. F., Henderson, A. S., Jacomb, P. A., Croft, L., and Easteal, S. (1997). Quantitative trait loci for neuroticism: an allelic association study with the serotonin receptor (HTR2) and monoamine oxidase A (MAOA) genes. Pers. Individ. Dif. 22, 287-290. doi: 10.1016/S0191-8869(96)00200-0

Kandler, C., Bleidorn, W., Riemann, R., Angleitner, A., and Spinath, F. M. (2012). Life events as environmental states and genetic traits and the role of personality: a longitudinal twin study. Behav. Genet. 42, 57-72. doi: 10.1007/s10519-011-9491-0

Karayiorgou, M., Sobin, C., Blundell, M. L., Galke, B. L., Malinova, L., Goldberg, P., et al. (1999). Family-based association studies support a sexually dimorphic effect of COMT and MAOA on genetic susceptibility to obsessive-compulsive disorder. Biol. Psychiatry 45, 1178-1189. doi: 10.1016/S0006-3223(98)00 319-9

Kim-Cohen, J., Caspi, A., Taylor, A., Williams, B., Newcombe, R., Craig, I. W., et al. (2006). MAOA, maltreatment, and gene-environment interaction predicting children's mental health: new evidence and a meta-analysis. Mol. Psychiatry 11, 903-913. doi: 10.1038/sj.mp.4001851

Kinnally, E. L., Huang, Y. Y., Haverly, R., Burke, A. K., Galfalvy, H., Brent, D. P., et al. (2009). Parental care moderates the influence of MAOA-uVNTR genotype and childhood stressors on trait impulsivity and aggression in adult women. Psychiatr. Genet. 19:126. doi: 10.1097/YPG.0b013e32832a50a7

Kisbu-Sakarya, Y., MacKinnon, D. P., and Aiken, L. S. (2013). A monte carlo comparison study of the power of the analysis of covariance, simple difference, and residual change scores in testing two-wave data. Educ. Psychol. Meas. 73, 47-62. doi: 10.1177/0013164412450574

Liu, L., Guan, L. L., Chen, Y., Ji, N., Li, H. M., Li, Z. H., et al. (2011). Association analyses of MAOA in Chinese Han subjects with attentiondeficit/hyperactivity disorder: family-based association test, case-control study, and quantitative traits of impulsivity. Am. J. Med. Genet. B 156, 737-748. doi: 10.1002/ajmg.b.31217

Livesley, W. J. (2001). Handbook of Personality Disorders: Theory, Research, and Treatment. New York, NY: The Guilford Press.

Lo, M. T., Hinds, D. A., Tung, J. Y., Franz, C., Fan, C. C., Wang, Y., et al. (2017). Genome-wide analyses for personality traits identify six genomic loci and show correlations with psychiatric disorders. Nat. Genet. 49:152. doi: $10.1038 /$ ng.3736 
Luciano, M., Hagenaars, S. P., Davies, G., Hill, W. D., Clarke, T.-K., Shirali, M., et al. (2017). 116 independent genetic variants influence the neuroticism personality trait in over 329,000 UK Biobank individuals. bioRxiv 168906. doi: $10.1101 / 168906$

Luciano, M., Huffman, J. E., Arias-Vásquez, A., Vinkhuyzen, A. A., Middeldorp, C. M., Giegling, I., et al. (2012). Genome-wide association uncovers shared genetic effects among personality traits and mood states. Am. J. Med. Genet. B. 159, 684-695. doi: 10.1002/ajmg.b.32072

Mackay, T. F. (2001). The genetic architecture of quantitative traits. Annu. Rev. Genet. 35, 303-339. doi: 10.1146/annurev.genet.35.102401.090633

Manuck, S. B., Flory, J. D., Ferrell, R. E., Mann, J. J., and Muldoon, M. F. (2000). A regulatory polymorphism of the monoamine oxidaseA gene may be associated with variability in aggression, impulsivity, and central nervous system serotonergic responsivity. Psychiatry Res. 95, 9-23. doi: 10.1016/S0165-1781(00)00162-1

Marsh, H. W., Balla, J. R., and McDonald, R. P. (1988). Goodness-of-fit indexes in confirmatory factor analysis: the effect of sample size. Psychol. Bull. 103, 391-410. doi: 10.1037/0033-2909.103.3.391

Marsh, H. W., Hau, K. T., and Grayson, D. A. (2005). "Goodness of fit evaluation in structural equation modeling," in Contemporary Psychometrics. A festschrift to Roderick, eds A. Maydeu-Olivares, J. J. McArdle and P. McDonald (Mahwah, NJ: Lawrence Erlbaum Associates, Inc.), 225-340

Marsh, H. W., Hau, K. T., and Wen, Z. (2004). In search of golden rules: comment on hypothesis-testing approaches to setting cutoff values for fit indexes and dangers in overgeneralizing $\mathrm{Hu}$ and Bentler's (1999) Findings. Struct. Equat. Model. 11, 320-341. doi: 10.1207/s15328007sem1103_2

McArdle, J. J. (2009). Latent variable modeling of differences and changes with longitudinal data. Annu. Rev. Psychol. 60, 577-605. doi: 10.1146/annurev.psych.60.110707.163612

McArdle, J. J., and Hamagami, F. (2001). "Latent difference score structural models for linear dynamic analyses with incomplete longitudinal data," in Decade of Behavior. New Methods for the Analysis of Change, eds L. M. Collins and A. G. Sayer (Washington, DC: American Psychological Association), 139-175.

McArdle, J. J., and Prindle, J. J. (2008). A latent change score analysis of a randomized clinical trial in reasoning training. Psychol. Aging 23, 702. doi: $10.1037 / \mathrm{a} 0014349$

McCoach, D. B., Black, A. C., and O'Connell, A. A. (2007). Errors of inference in structural equation modeling. Psychol. Sch. 44, 461-470. doi: 10.1002/pits. 20238

Meyer, J. H., Ginovart, N., Boovariwala, A., Sagrati, S., Hussey, D., Garcia, A., et al. (2006). Elevated monoamine oxidase a levels in the brain: an explanation for the monoamine imbalance of major depression. Arch. Gen. Psychiatry 63, 1209-1216. doi: 10.1001/archpsyc.63.11.1209

Meyer-Lindenberg, A., Buckholtz, J. W., and Kolachana, B. (2006). Neural mechanisms of genetic risk for impulsivity and violence in humans. Proc. Natl. Acad. Sci. U.S.A. 103, 6269-6274. doi: 10.1073/pnas.051131110

Millsap, R. E. (2010). Testing measurement invariance using item response theory in longitudinal data: an introduction. Child Dev. Perspect. 4, 5-9. doi: 10.1111/j.1750-8606.2009.00109.x

Muthén, L. K., and Muthén, B. O. (2015). Mplus User's Guide. Los Angeles, CA: Muthen \& Muthen.

Naumova, O. Y., Lee, M., Rychkov, S. Y., Vlasova, N. V., and Grigorenko, E. L. (2013). Gene expression in the human brain: the current state of the study of specificity and spatiotemporal dynamics. Child Dev. 84, 76-88. doi: 10.1111/cdev.12014

Nicotra, A., Pierucci, F., Parvez, H., and Senatori, O. (2004). Monoamine oxidase expression during development and aging. Neurotoxicology 25, 155-165. doi: 10.1016/S0161-813X(03)00095-0

Okbay, A., Baselmans, B. M., De Neve, J.-E., Turley, P., Nivard, M. G., Fontana, M. A., et al. (2016). Genetic variants associated with subjective wellbeing, depressive symptoms, and neuroticism identified through genome-wide analyses. Nat. Genet. 48, 624-633. doi: 10.1038/ng1216-1587b

Ouellet-Morin, I., Côt,é, S. M., Vitaro, F., Hébert, M., Carbonneau, R., Lacourse, É.,et al. (2016). Effects of the MAOA gene and levels of exposure to violence on antisocial outcomes. Br. J. Psychiatry 208, 42-48. doi: 10.1192/bjp.bp.114.162081

Pedersen, N. L., Oreland, L., Reynolds, C., and McClearn, G. E. (1993). Importance of genetic effects for monoamine oxidase activity in thrombocytes in twins reared apart and twins reared together. Psychiatry Res. 46, 239-251. doi: 10.1016/0165-1781(93)90092-U

Pilia, G., Chen, W. M., Scuteri, A., Orr,ú, M., Albai, G., Dei, M., et al. (2006). Heritability of Cardiovascular and personality traits in 6,148 Sardinians. PLoS Genet. 2:e132. doi: 10.1371/journal.pgen.0020132

Pinsonneault, J. K., Papp, A. C., and Sadee, W. (2006). Allelic mRNA expression of X-linked monoamine oxidase a (MAOA) in human brain: dissection of epigenetic and genetic factors. Hum. Mol. Genet. 15, 2636-2649. doi: $10.1093 / \mathrm{hmg} / \mathrm{ddl} 192$

Plomin, R., Owen, M. J., and McGuffin, P. (1994). The genetic basis of complex human behaviors. Science 264:1733. doi: 10.1126/science.8209254

Roberts, B. W., and DelVecchio, W. F. (2000). The rank-order consistency of personality traits from childhood to old age: a quantitative review of longitudinal studies. Psychol. Bull. 126:3. doi: 10.1037/0033-2909.126.1.3

Roberts, B. W., Wood, D., and Caspi, A. (2008). “The development of personality traits in adulthood," in Handbook of Personality: Theory and Research, eds O. P. John, R. W. Robins, and L. A. Pervin (New York, NY: Guilford Press), 375-398.

Rousseau, K., Vinall, L. E., Butterworth, S. L., Hardy, R. J., Holloway, J., Wadsworth, M. E. J. et al., (2006). MUC7 Haplotype analysis: results from a longitudinal birth cohort support protective effect of the MUC7*5 allele on respiratory function. Anna. Hum. Genet. 70, 417-427. doi: 10.1111/j.1469-1809.2006.00250.x

Sabol, S. Z., Hu, S., and Hamer, D. (1998). A functional polymorphism in the monoamine oxidase A gene promoter. Hum. Genet. 103, 273-279. doi: $10.1007 / \mathrm{s} 004390050816$

Scerif, G., and Karmiloff-Smith, A. (2005). The dawn of cognitive genetics? Crucial developmental caveats. Trends in Cognit. Sci. 9, 126-135. doi: 10.1016/j.tics.2005.01.008

Sebastian, C. L., Roiser, J. P., Tan, G. C., Viding, E., Wood, N. W., and Blakemore, S. J. (2010). Effects of age and MAOA genotype on the neural processing of social rejection. Genes Brain Behav. 9, 628-637. doi: 10.1111/j.1601-183X.2010.00596.x

Shiraishi, H., Suzuki, A., Fukasawa, T., Aoshima, T., Ujiie, Y., Ishii, G. et al. (2006) Monoamine oxidase A gene promoter polymorphism affects novelty seeking and reward dependence in healthy study participants. Psychiatr. Genet. 16, 55-58. doi: 10.1097/01.ypg.0000199447.62044.ef

Smyrnis, N., Kattoulas, E., Stefanis, N. C., Avramopoulos, D., Stefanis, C. N., and Evdokimidis, I. (2009). Schizophrenia-related Neuregulin-1 single-nucleotide polymorphisms lead to deficient smooth eye pursuit in a large sample of young men. Schizophr. Bull. 37, 822-831. doi: 10.1093/schbul/sbp150

Soto, C. J., John, O. P., Gosling, S. D., and Potter, J. (2011). Age differences in personality traits from 10 to 65 : big five domains and facets in a large cross-sectional sample. J. Pers. Soc. Psychol. 100:330. doi: 10.1037/ a0021717

Specht, J., Egloff, B., and Schmukle, S. C. (2011). Stability and change of personality across the life course: the impact of age and major life events on meanlevel and rank-order stability of the Big Five. J. Pers. Soc. Psychol. 101:862. doi: $10.1037 / \mathrm{a} 0024950$

Tassone, F., Qi, L., Zhang, W., Hansen, R. L., Pessah, I. N., and Hertz-Picciotto, I. (2011). MAOA, DBH, and SLC6A4 variants in CHARGE: a case-control study of autism spectrum disorders. Autism Res. 4, 250-261. doi: 10.1002/aur.196

Taylor, A., and Kim-Cohen, J. (2007). Meta-analysis of gene-environment interactions in developmental psychopathology. Dev. Psychopathol. 19, 1029-1037. doi: 10.1017/S095457940700051X

Terracciano, A., Sanna, S., Uda, M., Deiana, B., Usala, G., Busonero, F., et al. (2010). Genome-wide association scan for five major dimensions of personality. Mol. Psychiatry 15:647. doi: 10.1038/mp.2008.113

Thomas, D. R., and Zumbo, B. D. (2012). Difference Scores from the point of view of reliability and repeated-Measures ANOVA In Defense of Difference scores for data analysis. Educ. Psychol. Meas. 72, 37-43. doi: 10.1177/0013164411409929

Thorpe, L. W., Westlund, K. N., Kochersperger, L. M., Abell, C. W., and Denney, R. M. (1987). Immunocytochemical localization of monoamine oxidases A and B in human peripheral tissues and brain. J. Histochem. Cytochem. 35, 23-32. doi: $10.1177 / 35.1 .3025289$

Tsonaka, R., van der Helm-van Mil, A. H., and Houwing-Duistermaat, J. J. (2012). A two-stage mixed-effects model approach for gene-set analyses in candidate gene studies. Stat. Med. 31, 1190-1202. doi: 10.1002/sim.4370 
Tsuchimine, S., Yasui-Furukori, N., Kaneda, A., Saito, M., Nakagami, T., Sato, K. et al. (2008). Association between monoamine oxidase A (MAOA) and personality traits in Japanese individuals. Prog. Psychopharmacol. Biol. Psychiatry 32, 1932-1935. doi: 10.1016/j.pnpbp.2008.09.012

van den Berg, S. M., de Moor, M. H., Verweij, K. J., Krueger, R. F., Luciano, M., Arias Vasquez, A., et al. (2016). Meta-analysis of genome-wide association studies for extraversion: findings from the Genetics of Personality Consortium. Behav. Genet. 46, 170-182. doi: 10.1007/s10519-015-9735-5

van der Sluis, S., Verhage, M., Posthuma, D., and Dolan, C. V. (2010). Phenotypic complexity, measurement bias, and poor phenotypic resolution contribute to the missing heritability problem in genetic association studies. PLOS ONE 5:e13929. doi: 10.1371/journal.pone.0013929

Verma, D., Chakraborti, B., Karmakar, A., Bandyopadhyay, T., Singh, A. S., Sinha, S., et al. (2014). Sexual dimorphic effect in the genetic association of monoamine oxidase A (MAOA) markers with autism spectrum disorder. Prog. Neuro-Psychopharmacol. Biol. Psychiatry 50, 11-20. doi: 10.1016/j.pnpbp.2013.11.010

Vernon, P. A., Martin, R. A., Schermer, J. A., and Mackie, A. (2008). A behavioral genetic investigation of humor styles and their correlations with the Big-5 personality dimensions. Pers. Individ. Dif. 44, 1116-1125. doi: 10.1016/j.paid.2007.11.003

Vinkhuyzen, A. A., Pedersen, N. L., Yang, J., Lee, S. H., Magnusson, P. K., Iacono, W. G., et al. (2012). Common SNPs explain some of the variation in the personality dimensions of neuroticism and extraversion. Transl. Psychiatry 2:e102. doi: 10.1038/tp.2012.27

Vitalis, T., Fouquet, C., Alvarez, C., Seif, I., Price, D., Gaspar, P., et al. (2002). Developmental expression of monoamine oxidases A and B in the central and peripheral nervous systems of the mouse. J. Comp. Neurol. 442, 331-347. doi: 10.1002/cne.10093

Wadsworth, M. E., Butterworth, S. L., Hardy, R. J., Kuh, D. J., Richards, M., Langenberg, C., et al. (2003). The life course prospective design: an example of benefits and problems associated with study longevity. Soc. Sci. Med. 57, 2193-2205. doi: 10.1016/S0277-9536(03)00083-2

Wray, N. R., Birley, A. J., Sullivan, P. F., Visscher, P. M., and Martin, N. G. (2007). Genetic and phenotypic stability of measures of neuroticism over 22 years. Twin Res. Hum. Genet. 10, 695-702. doi: 10.1375/twin.10.5.695
Wu, J. B., Chen, K., Li, Y., Lau, Y. F. C., and Shih, J. C. (2009). Regulation of monoamine oxidase A by the SRY gene on the Y chromosome. FASEB J. 23, 4029-4038. doi: 10.1096/fj.09-139097

Xu, M. K., Gaysina, D., Barnett, J. H., Scoriels, L., van de Lagemaat, L. N., Wong, A., et al. (2015). Psychometric precision in phenotype definition is a useful step in molecular genetic investigation of psychiatric disorders. Transl. Psychiatry 5:e593. doi: 10.1038/tp. 2015.86

Yu, C.-Y. (2002). Evaluating Cutoff Criteria of Model fit Indices for Latent Variable Models with Binary and Continuous Outcomes. Los Angeles, CA: University of California Los Angeles.

Yu, Y. W., Yang, C. W., Wu, H. C., Tsai, S. J., Hong, C. J., Chen, M. C., et al. (2005), Association study of a functional MAOA-uVNTR gene polymorphism and personality traits in Chinese young females. Neuropsychobiology 52, 118-121. doi: 10.1159/000087556

Zhang, Y., Ming, Q., Wang, X., and Yao, S. (2016). The interactive effect of the MAOA-VNTR genotype and childhood abuse on aggressive behaviors in Chinese male adolescents. Psychiatr. Genet. 26, 117-123. doi: 10.1097/YPG.0000000000000125

Zuckerman, M., and Cloninger, C. R. (1996). Relationships between Cloninger's, Zuckerman's, and Eyesenck's dimensions of personality. Pers. Individ. Dif. 21, 283-285. doi: 10.1016/0191-8869(96)00 $042-6$

Conflict of Interest Statement: The authors declare that the research was conducted in the absence of any commercial or financial relationships that could be construed as a potential conflict of interest.

Copyright (๑) 2017 Xu, Gaysina, Tsonaka, Morin, Croudace, Barnett, HouwingDuistermaat, Richards, Jones and the LHA Genetics Group. This is an open-access article distributed under the terms of the Creative Commons Attribution License (CC BY). The use, distribution or reproduction in other forums is permitted, provided the original author(s) or licensor are credited and that the original publication in this journal is cited, in accordance with accepted academic practice. No use, distribution or reproduction is permitted which does not comply with these terms. 